\title{
SEMANTIC PROCESSING IN CHILDREN WITH AUTISM SPECTRUM DISORDER
}

\author{
Verónica Moreno-Campos \\ University of Valencia \\ veronica.moreno@uv.es \\ Maite Montagut-Asunción \\ Catholic University of Valencia \\ maite.montagut@ucv.es \\ Gemma Pastor-Cerezuela \\ University of Valencia \\ gemma.pastor@uv.es
}

Recepción Artículo: 16 septiembre 2020

Admisión Evaluación: 21 octubre 2020

Informe Evaluador 1: 25 noviembre 2020

Informe Evaluador 2: 23 noviembre 2020

Aprobación Publicación: 27 noviembre 2020

\section{ABSTRACT}

The present study analyzed the semantic processing of a group of children with autism spectrum disorder (n $=24$ ), with the main objective of finding out whether they present differences compared to a group of children with typical development $(n=24)$. For this purpose, an analysis was carried out of the content of the items on the information subtest of the WPPSY-III, establishing a series of categories depending on the type of semantic demand required: signifier-signified association, experiential relationship, and general knowledge. The results obtained support the idea that children with autism would carry out a semantic processing of information in the same way as children without autism, but they would need more time to assume and establish such semantic processing.

Keywords: semantic processing; autism; lexical access; meaning.

Understanding the meaning of words is critical to accessing the representation of the whole word. Language is the human's ability to translate the facts, objects and actions in which we are involved into words. Linking the concept with the associated word, that is, establishing the word's meaning, is made possible through semantic processing. An important issue in cognitive science is the way meanings are represented and categorized in the human cognitive system. To study this issue, it is necessary to consider two levels of knowledge. The first is the psycholinguistic level, where the common characteristics of related meanings form semantic networks (Bean, Fein \& Naigles, 2016; De Deyne, Verheyen \& Storms, 2016; Ma, 2013). The second is the neuropsychological level, where many studies try to find the neural correlates of linguistic networks in semantic processing (Betta et al., 2018; Moritz-Gasser, Herbet \& Duffau, 2013; Weiss, Cweigenberg \& Booth, 2018).

At the psycholinguistic level, it is necessary to emphasize Prototype Theory (Rosch, 1977, 1978, 1988; Wittgenstein, 1988), which explains how semantic categories are organized in a taxonomy of hierarchical struc- 


\section{SEMANTIC PROCESSING IN CHILDREN WITH AUTISM SPECTRUM DISORDER}

tures. These categories are determined by the relationship between inter-category discrimination and intra-category semantic similarity, and not independently from each other. Thus, there is a meaning (prototype) that has all the attributes we consider in a category (e.g. domestic animal, prototype: dog), and we categorize it in terms of the equality / difference of relational meanings such as cat, fish, or elephant. This linguistic theory is related to Perceptual Symbol Systems (Barsalou, 1999), which propose that semantic knowledge is grounded in sensorimotor experience. Both theories could explain how children establishing relationships between meanings and the associated words as they are growing and understanding the world around them.

There are two ways to name meanings. First, in associating a meaning with a word (e. g. "What's this? This is a table"), the child must have previously experienced the meaning (the object, fact, or action itself) and then associated it with the attributed name. In this case, the association can involve joining a referent or word with the concept, and we would say that the child "knows a new word", or, at a second level, a relationship can be established between what is experienced by the child due to contact with the concept and the word. For example, when experiencing disagreeable contact with a dog, a child can feel fear and associate this feeling only with the specific word or s/he can generalize it to the animal genus. However, a child who has had a good experience with another dog will relate the word "dog" to more positive attributes. In this act, the child joins the word with the semantic characteristics observed in the meaning, and the establishment of similar attributes of other words would make up a semantic network based on the child's experiential knowledge of the world. Second, in the non-experiential way, that is, the general knowledge from which children learn the relationship between a word and its meaning (e.g. "an ocean is a large body of water"), this relationship between meaning and word often has to be memorized.

Although some studies have established how children with typical development (TD) acquire meaning (Espinosa Ochoa \& Orozco Arreola, 2018; Fisher, Godwin, Matlen \& Unger, 2014), as far as we know, few studies have done so in children with autism spectrum disorder (ASD) using a purely psycholinguistic perspective. We can highlight the studies by Arunachalam and Luyster (2016), and Eigsti and Schuh (2016), who have focused on the processes underlying the lexical access of children with autism. The majority of the previous studies at the neuropsychological level have focused on identifying brain processing differences between children with and without ASD using neuroimaging techniques (DiStefano, Senturk \& Jeste, 2019; Ribeiro, Valasek, Minati \& Boggio, 2013; McCleery et al., 2010; Mendez, Sanz, Abril \& Valdizan, 2009). Results show substantial heterogeneity in performance, as well as differences depending on the proposed task: whereas the Ribeiro et al., (2013) and McCleery et al., (2010) studies found different responses in children with and without ASD, the Mendez et al., (2009) and DiStefano et al., (2019) studies showed a similar semantic processing pattern, although the ASD group "is characterized by delayed speed of processing and limited integration with mental representations" (DiStefano et al., 2019, p. 100640).

The present study points to the relevance of the psycholinguistic level of semantic processing in determining whether children with and without ASD present similar or different response patterns on a certain task. Eigsti, de Marchena, Schuh \& Kelley (2011) concluded that children with ASD present difficulties with social communication that may affect language development in terms of the way they process the linguistic input in their environment. As Arunachalam and Luyster (2018) suggested when discussing lexical development in children with ASD, "the intake of the input and thus the linguistic representation that they form are constrained by their own linguistic and cognitive abilities" (Arunachalam \& Luyster, 2018, p. 2660).

In this study, we want to find out whether children with and without ASD present different responses on the Information task of the WPPSI-III test (Wechsler, 2009). We have chosen this task because it provides different semantic tasks where children have to give the correct answer. Some questions require matching the word and its meaning (e. g. "point to your nose"), other questions are based on the experiential knowledge of the speaker (e. g. "which object is used to eat?"), and others ask for general and memory knowledge (e. g. "names of oceans").

With the main objective of determining whether the patterns of children with ASD are similar to or different from those of children without ASD, our hypothesis was that both groups' answers would be better on experiential 
items than on knowledge items. Experiential questions are based on actions or facts that children could have experienced and their relationship with a specific memory or object, whereas knowledge questions have to do with abstract concepts. Moreover, we predicted that children without ASD would obtain higher scores than the ASD group in all semantic categories.

\section{METHODS}

\section{Participants}

In the present study, a total of 48 children participated, with ages from 5 to 7 years old and a non-verbal IQ ranging from 75 to 135 on the Raven test (Raven, 1996). The 48 children spoke Spanish as their first language. The ASD group ( $n=24$ ) was composed of 19 males and 5 females with a mean age of 6.27 years $(S D=1.00)$, a mean non-verbal IQ of $96.54(S D=17.68)$, and a mean verbal IQ of $70.42(S D=19.11)$ on the Peabody test (Dunn, Dunn \& Arribas, 2006). The comparison group $(n=24)$ was composed of 21 males and 3 females with a mean age of 6.68 years $(S D=1.22)$, a mean non-verbal IQ of $100.88(S D=18.26)$, and a mean verbal IQ of 97.29 $(S D=12.88)$ on the Peabody test.

Children in the ASD group had a clinical diagnosis of ASD, according to the DSM-IV-TR criteria (APA, 2000), and they met the diagnostic criteria for level 2 of the DSM-5 (APA, 2013). They had been diagnosed by neuropediatric services from different hospitals in the national health system. These neuropediatric services were responsible for checking compliance with the diagnostic criteria. They referred the children who met the diagnostic criteria to early care units where the diagnosis was confirmed using a more specific instrument, the Autism Diagnostic Observation Schedule (ADOS) (Lord, Rutter, DiLavore \& Risi, 2000), which was applied by specialized psychologists who had formal training in using this instrument. Moreover, all of them obtained an Autism Index score $\geq 85$ on the Gilliam Autism Rating Scale, Second Edition (GARS-2), indicating a high likelihood of the disorder (Gilliam, 2006). The scores on the GARS-2 ranged from 85 to $135(\mathrm{M}=95.25, \mathrm{SD}=8.30)$. The children in the ASD group were attending schools with specific classrooms in which the Treatment and Education of Autistic and Related Communication Handicapped Children (TEACCH) methodology was carried out. These are integrated classrooms included in regular state schools in Valencia (Spain) where students with disorders affecting language and communication are enrolled. The children in the comparison group had typical development, with no clinical diagnosis, and they attended the same schools as the ASD group, but in the regular modality.

Initially, the ASD group was composed of a total of 67 children from the 18 schools that voluntarily agreed to participate, but 43 children were excluded from the study for different reasons, such as not being able to understand the Raven test, not having oral language, or not receiving their parents' informed consent. The comparison group was initially made up of 350 children who attended 11 of the 18 schools where the children with ASD were enrolled. The two groups of children were matched one-to-one on non-verbal IQ, chronological age, and gender, so that of the initial group of 350 children without ASD, 24 were selected.

No statistically significant differences were found between the two groups of children on gender ( ${ }^{2}=0.600$, $p=.439)$, chronological age $\left(F_{(1,46)}=1.57, p=.217\right)$, or non-verbal IQ $(F(1,46)=0.69, p=.408)$. Nonetheless, statistically significant differences were found on verbal $I Q(F(1,46)=32.63, p=.001)$, which was higher in the comparison group than in the ASD group.

\section{Ethics Statement}

This study was approved by the University of Valencia and had the official authorization of the General Direction and School Management, the agency responsible for primary education. The parents of the children gave written informed consent to participate in the research. 


\section{SEMANTIC PROCESSING IN CHILDREN WITH AUTISM SPECTRUM DISORDER}

\section{Procedures}

Each child's non-verbal IQ, verbal IQ, and performance on the Information subtest of the WSSPI-III (Wechsler, 2009) were individually evaluated by the school psychologist in a noise- and distraction-free office. In all cases, the tasks were administered on different days and in the same order (first: non-verbal IQ task, second: verbal IQ task, and third: Information subtest of the WSSPI-III). Information about autism symptoms was obtained from the GARS-2 (Gilliam, 2006) by means of an interview with the parents of the ASD group.

\section{Instruments}

Information Subtest of the WSSPI-III (Wechsler, 2009). This subtest belongs to the WSSPI-III Verbal Scale. It assesses the child's ability to acquire, conserve, and recover knowledge about general events, and it is related to crystalized intelligence, long-term memory, and the ability to recall information taken from our surroundings. It is composed of 34 items: 6 graphic items, on which the child must choose the drawing we name from four possibilities, and 28 verbal items, on which the child must answer general knowledge questions, such as: "What are shoes made of?"; or "What day comes after Saturday?". The child receives 0 or 1 point depending on his/her answer.

For the present study, the items on the subtest were grouped in a total of three categories depending on the type of semantic demand required. The established categories were the following: (1) Signifier-signified (3 items), consisting of items that assess the ability to link a word with its corresponding meaning; (2) Experiential (11 items), consisting of items that involve the identification of a word depending on the user's personal experience with it; and (3) General knowledge (20 items), consisting of items that assess the encyclopedic knowledge acquired about concepts. Two expert philologists in Linguistics independently performed the assignment of the items to the three categories. The kappa index of coincidence between the two raters in assigning the items to the three categories yielded a result of 0.81 .

\section{Data analysis}

Qualitative and quantitative analyses were performed. In the case of the qualitative analysis, a content study was conducted of the 34 items on the Information Subtest of the WPPSI-III (Wechsler, 2009) in order to group them in the three categories established according to the type of semantic demand required (see the last paragraph of the previous section). The quantitative analyses were performed using the SPSS version 24 statistical package. First, multivariate analyses of variance (MANOVA) and the corresponding confirmation ANOVAS were carried out to compare the two groups on their performance (correct answers) on the three categories established from the Information subtest of the WPPSI-III. Second, within each group, repeated-measures multivariate analysis of the three categories was carried out, based on the percentages of correct answers obtained in each category, and post hoc comparison tests were performed.

\section{RESULTS}

\section{Group differences in the three categories from the Information subtest of the WPPSI-III.}

To compare the performance of the two groups in each of the three categories established from the Information subtest of the WPPSI-III (signifier-signified, experiential, and general knowledge), the performance indicator used was the number of correct answers obtained in each category. The result of the MANOVA between the two groups was: Wilks' Lambda $=.593, F(3,44)=10.06, p<.001,{ }^{2} p=.41$, indicating the presence of statistically significant differences between the two groups. The confirmation ANOVAS and the between-group comparisons yielded statistically significant differences between the two groups in all the categories, with the comparison group scoring higher than the ASD group in all cases (see table 1). 
Table 1. Group differences in the three categories from the Information subtest of the WPPSI-III (Wechsler, 2009).

\begin{tabular}{|c|c|c|c|c|c|c|}
\hline & & $\begin{array}{c}\text { ASD } \\
\text { group } \\
(n=24 \\
)\end{array}$ & $\begin{array}{c}\text { Compariso } \\
\text { n } \\
\text { group } \\
(n=24)\end{array}$ & $F_{1,46}$ & $\eta^{2}$ & $\begin{array}{c}\text { Differences } \\
\text { between } \\
\text { groups }\end{array}$ \\
\hline \multirow{2}{*}{$\begin{array}{l}\text { Signifier-Signified } \\
\text { (SS) }\end{array}$} & $\mathrm{M}$ & 2.25 & 2.92 & \multirow{2}{*}{$\begin{array}{r}19.89 * \\
*\end{array}$} & \multirow{2}{*}{$\begin{array}{r}0.30 \\
2\end{array}$} & \multirow{2}{*}{$\begin{array}{c}\text { ASD group } \\
\text { Comparison } \\
\text { group }\end{array}$} \\
\hline & SD & 0.68 & 0.28 & & & \\
\hline \multirow{2}{*}{$\begin{array}{l}\text { Experiential } \\
(\text { EXP) }\end{array}$} & M & 8.71 & 11.00 & \multirow{2}{*}{$\begin{array}{r}19.46^{*} \\
*\end{array}$} & \multirow{2}{*}{$\begin{array}{r}0.29 \\
7\end{array}$} & \multirow{2}{*}{$\begin{array}{c}\text { ASD group < } \\
\text { Comparison } \\
\text { group }\end{array}$} \\
\hline & SD & 2.54 & 0.00 & & & \\
\hline \multirow[t]{2}{*}{ General knowledge (G] } & M & 9.83 & 14.17 & \multirow{2}{*}{$\begin{array}{r}14.22 * \\
*\end{array}$} & \multirow{2}{*}{$\begin{array}{r}0.23 \\
6\end{array}$} & \multirow{2}{*}{$\begin{array}{c}\text { ASD group } \\
\text { Comparison } \\
\text { group }\end{array}$} \\
\hline & SD & 4.65 & 3.17 & & & \\
\hline
\end{tabular}

Intra-group differences in the three categories from the Information subtest of the WPPSI-III.

In order to analyze the performance within each group depending on the category, the percentages of correct answers in each category were used to perform the statistical analyses. The results of the repeated-measures multivariate analysis of the three categories proposed (signifier-signified, experiential, and general knowledge) within each group showed statistically significant differences in some cases: specifically, the performance on the signifier-signified and experiential categories was higher than the performance on the general knowledge category in the two groups of children (see table 2).

Table 2. Intra-group differences in the three categories from the Information subtest of the WPPSI-III (Wechsler, 2009).

\begin{tabular}{lccccccc}
\hline & & SS & EXP & GK & $F_{1,46}$ & $\eta^{2}$ & $\begin{array}{c}\text { Differences among } \\
\text { categories }\end{array}$ \\
\hline ASD group $(n$ & $\mathrm{M}$ & 73.6 & 79.16 & 49.16 & $13.39^{*}$ & .728 & $\mathrm{GK}<\mathrm{SS}, \mathrm{EXP}$ \\
$=24)$ & $\mathrm{SD}$ & 24.0 & 23.13 & 23.25 & & & \\
Comparison & $\mathrm{M}$ & 98.6 & 100.0 & 70.83 & $39.26^{*}$ & .631 & $\mathrm{GK}<\mathrm{SS}, \mathrm{EXP}$ \\
group $(n=24)$ & $\mathrm{SD}$ & 6.80 & 0.00 & 15.86 & & & \\
\hline
\end{tabular}

Note: SS: Signifier-Signified; EXP: Experiential; GK: General knowledge.

\section{DISCUSSION}

The present study analyzed the semantic processing of a group of children with ASD, with the main objective of finding out whether they present differences compared to a group of children with TD. For this purpose, an analysis was carried out of the content of the items on the information subtest of the WPPSY (Wechsler, 2009), establishing a series of categories depending on the type of semantic demand required: signifier-signified, experiential, and general knowledge.

First, the comparison of the two groups' performance in each of the three categories produced the expected results; that is, the group without ASD obtained higher scores than the ASD group in all the categories. This result indicates that the processes followed by the group of children with TD were more effective than those utilized by the group of children with ASD. 


\section{SEMANTIC PROCESSING IN CHILDREN WITH AUTISM SPECTRUM DISORDER}

Second, the results of the present study also show that the ASD group obtained the best results in the categories related to concepts that enter or have entered directly through their life experience (experiential and signifier-signified). Despite obtaining lower scores than those of the comparison group, the children with ASD activated the experiential route as the main path in recovering information when generating the meaning of a word. This association is related to the theory of prototypes, which states that individuals organize categories in the everyday world according to the attributes of each concept and the relationships established with them. The more experience the subject has with a concept, the less cognitive effort he/she will need to activate its meaning, given that various characteristics will refer to it. By contrast, when a concept is only acquired through the memory route, greater cognitive effort is required to recover its meaning, given that the network of characteristics that compose it will only be activated from the memory or associative chain through which it was acquired. In this regard, we find studies and clinical practices that support experiential learning in ASD as the main way to consolidate knowledge (Conn, 2013; Peterson, 2012). The fact that the ASD group obtained some of its best scores in the signifier/signified category can be related to the fact that some questions (e. g. "what is this finger called?") refer to an unambiguous association between signifier and signified, and no contextual clue is needed to access this relationship.

In addition, the fact that the worst results were obtained for the general knowledge category can probably be explained by the format and conditions presented by the concepts generating semantic relations. For example, on the item "what shines in the sky at night?", three semantic nuclei are presented that must be combined to access the correct meaning. The qualitative analysis of the type of incorrect answers provided by the ASD group showed that the greatest index of errors was concentrated in the erroneous attribution of characteristics to the words. Thus, for the first nucleus of meaning, which is the concept "shine", the children provided responses associated with this meaning without taking into account the linguistic context of the sentence ("mirror", "shiny"). In response to a specific characteristic, the children with ASD activated a different semantic field from what would be expected based on the item's instructions because they did not consider all the semantic attributes of the sentence together.

This result would confirm the studies that point out that children with ASD present comprehension problems that are partly due to the rapid assignment of a word to its associated meaning, without previously analyzing and then selecting the related characteristics of the meanings contained in an instruction. These results indicate along the lines of the studies by $\mathrm{Ma}$ (2013) and Bean et al., (2016)- that the wrong semantic identification is the main source of semantic error. This semantic processing would explain, in turn, the problems that children with ASD have in understanding abstract meanings (Juillerat, Cornejo \& Castillo, 2015) or in pragmatic decoding, which requires the simultaneous processing of linguistic and contextual information (De Deyne et al., 2016).

Finally, both groups presented the same pattern: the highest scores were in the categories linked to the user's experience, and the lowest scores were in the category related to general knowledge. Thus, we can point out that, to recover this type of information, children with and without ASD activated the same required semantic processes, such as crystalized intelligence, long-term memory, auditory comprehension, the capacity for evocation, and the capacity for oral expression. The response pattern reveals that ASD children did the same things as children without ASD. However, the difference in the number of correct responses could be related to a different processing speed, which can lead children with ASD to show the same semantic processing as children without ASD, but slower.

Therefore, our results reinforce the idea that children with autism process information in the same way as children without autism, but they need more time to assume and establish semantic processing. Thus, we can point out that semantic learning benefits from experiential reinforcement in children with and without autism. This finding could challenge the prevailing view that learning environments should be made as simple as possible for children with ASD, in line with the conclusion of the study by Remington, Hanley, O'Brien, Riby, and Swettenham (2019). 


\section{Conclusions and General Implications for Practice}

In conclusion, our results reveal that children with ASD and children with typical development do not present differences in the semantic processing of concepts. Both groups show a preference for the experiential route as the main semantic categorization route. With regard to the practical implications of our study, the results reinforce the importance of fostering learning through real contexts. First, vocabulary acquisition is favored in children when the learning takes place through role-playing or applied activities where the children experiment with the relationships established between different words in a semantic field. Second, to foster semantic processing in children with ASD, it is important to work on the semantic relationships of the words that make up the same sentence. In this way, children with ASD can identify the common characteristics in the words in order to relate them and integrate them into the right context. Finally, the preferential system of semantic conceptual learning through the experiential route also explains the difficulties of children with ASD in consolidating abstract concepts such as phonological awareness (based on a memory-based relation). If this type of learning is complemented by applied procedures, such as the physical and visual reinforcement provided by a system such as cued speech, children with ASD can anchor memory-based knowledge to experiential events and, therefore, consolidate and incorporate the learning in an effective and natural way that respects their particular cognitive processing style.

\section{Limitations of the Study}

Our study presents some limitations that must be taken into account in interpreting and evaluating the reach of the results obtained. First, children with ASD with very low cognitive functioning were not part of this sample, and so the autism spectrum was not entirely represented. Second, this research used cross-sectional data and did not study the variables over time. Third, this research did not include a comparison group with a different psychological disorder -e.g., ADHD-, and so we cannot definitively conclude that the group differences are unique to autism. Finally, the differences found in the semantic codification processes between the two groups are only based on the results obtained from grouping the items from the Information subtest of the WPPSI-III (Wechsler, 2009) in three categories according to the semantic demand required. Although the grouping was performed through a content study of the items on the test carried out independently by two expert philologists in Linguistics, future studies should use other additional tests to assess semantic processing differences between children with and without ASD.

\section{BIBLIOGRAPHIC REFERENCES}

American Psychiatric Association (2000). Diagnostic and statistical manual of mental disorders (4th ed., text rev.). Washington, DC: Author.

American Psychiatric Association (2013). Diagnostic and statistical manual of mental disorders (5th ed.). Arlington, VA: American Psychiatric Publishing.

Arunachalam, S. \& Luyster, R. (2016). The integrity of lexical acquisition mechanisms in autism spectrum disorders: A research review. Autism Research, 9(8), 810-828. Doi: 10.1002/aur.1590

Arunachalam, S. \& Luyster, R. (2018). Lexical development in young children with autism spectrum disorder (ASD): how ASD may affect intake from the input. Journal of Speech, Language, and Hearing Research, 61, 2659-2672. Doi: 10.1044/2018_JSLHR-L-RSAUT-18-0024

Barsalou, L. W. (1999). Perceptual symbol systems. Behavioral and Brain Sciences, 22(4), 577-660. Doi: 10.1017/S0140525X99002149

Bean, A; Fein, D. \& Naigles, L. (2016). Category structure and processing in 6-year-old children with autism, Autism Research, 10(2), 327-336. Doi: 10.1002/aur.1652

Betta, M., Handjaras, G., Papaple, P., Rampinini, A., Malfatti, G., Pietrini, P., Turella, L., Ricciardi, E. \& Leo, A. (2018). MEG spectro-temporal patterns underlying semantic processing. International Journal of Psychophysiology, 131, S71. Doi: 10.1016/j.ijpsycho.2018.07.205 


\section{SEMANTIC PROCESSING IN CHILDREN WITH AUTISM SPECTRUM DISORDER}

Conn, C. (2013). Play based interventions for children and adolescents with autism spectrum disorders. Child and Adolescent Mental Health, 18 (2), 125-126. Doi: 10.1111/camh.12031

De Deyne, S., Verheyen, S. \& Storms, G. (2016). Structure and organization of the mental lexicon: a network approach derived from syntactic dependency relations and word associations. In A. Mekler et al. (Eds.) Towards a theoretical framework from analyzing complex linguistics networks, understanding complex systems, 47-79. Springer - Verlag Berlin Heidelberg. Doi: 10.1007/978-3-662-47238-5

DiStefano, C., Senturk, D., \& Jeste, S. S. (2019). ERP evidence of semantic processing in children with ASD. Developmental Cognitive Neuroscience, 36, 100640. Doi: 10.1016/j.dcn.2019.100640

Dunn, L. M., Dunn, L. M., \& Arribas, D. (2006). PPVT-III Peabody Picture Vocabulary Test. Madrid, Spain: TEA Editions.

Eigsti, I. M., de Marchena, A. B., Schuh, J. M., \& Kelley, E. (2011). Language acquisition in autism spectrum disorders: a developmental review. Research in Autism Spectrum Disorders, 5(2), 681-691. Doi: 10.1016/j.rasd.2010.09.001

Eigsti, I. M. \& Schuh, J. M., (2016). Language acquisition in ASD: Beyond standardized language measures. En Letitia N. \& Naigles (Ed.), Innovative investigations of language in autism spectrum disorder. 183-201. Washington, DC: American Psychological Association.

Espinosa Ochoa, M. \& Orozco Arreola, A. (2018). El desarrollo típico del español como lengua materna. En Cecilia Rojas Nieto y Elsa Viviana Oropeza Gracia (eds.), Diferencias individuales en la adquisición del lenguaje. Factores lingüísticos, cognitivos, socioambientales, 273-278. México: Universidad Nacional Autónoma de México.

Fisher, A., Godwin, K., Matlen, B. \& Unger, L. (2014). Development of category-based induction and semantic knowledge. Child Development, 86 (1), 48-62. Doi: 10.1111/cdev.12277

Gilliam, J. E. (2006). Gilliam Autism Rating Scale (2nd ed.). Madrid, Spain: Symtéc.

Juillerat, K, Cornejo, F. \& Castillo, R. (2015). Procesamiento semántico de palabras epistémicas y metafísicas en niños y adolescentes con trastorno de espectro autista (TEA) y desarrollo típico (DT). Terapia Psicológica, 33 (3), 221-238. Doi: 10.4067/S0718-48082015000300006

Lord, C., Rutter, M., DiLavore, P. C., \& Risi, S. (2000). Autism diagnostic observation schedule: ADOS manual. LA, US: Western Psychological Services.

Ma, X. (2013). Evocation: analyzing and propagating a semantic link based on free word association. Language Resources \& Evaluation, 47, 819-837. Doi: 10.1007/s10579-013-9219-2

McCleery, J. P., Ceponiene, R., Burner, K. M., Townsend, J., Kinnear, M. \& Schreibman, L. (2010). Neural correlates of verbal and non-verbal semantic integration in children with autism spectrum disorders. Journal of Child Psychology, 51 (3), 277-286. Doi: org/10.1111/j.1469-7610.2009.02157.x

Mendez, M., Sanz, O., Abril, B. \& Valdizan, J. R. (2009). Event-related potentials (N400) in autistic children. Clinical Neuropsychology, 120 (4), e136. Doi: 10.1016/j.clinph.2008.09.041.

Moritz-Gasser, S., Herbet, G. \& Duffau, H. (2013). Mapping the connectivity underlying multimodal (verbal and non-verbal) semantic processing: a brain electrostimulation study. Neuropsychologia, 51, 1814-1822. Doi: 10.1016/j.neuropsychologia.2013.06.007

Peterson, K. M. (2012). Nature, nurture, knowledge: The promise of experiential learning for students with special needs. Doctoral Dissertation. Northeastern University.

Raven, J. C. (1996). Matrices Progresivas. Escalas CPM Color y SPM General. TEA Ediciones: Madrid.

Remington, A, Hanley, M., O'Brien, S., Riby, D. \& Swettenham, J. (2019). Implications for capacity in the classroom: simplifying tasks for autistic children may not be the answer. Research in Development Disabilities, 85, 197-204. Doi: 10.1016/j.ridd.2018.12.006

Ribeiro, T.C., Valasek, C.A., Minati, L. \& Boggio, P.S. (2013). Altered semantic integration in autism beyond language. Neuroreport, 24 (8), 414-418. Doi: 10.1097/WNR.0b013e328361315e. 
Rosch, E. (1977). Human categorization. In N. Warren (Ed.): Studies in Cross-Cultural Psychology. London: Academic Press.

Rosch, E. (1978). Principles of Categorization, in E. Rosch \& B. Lloyd (Eds.): Cognition and Categorization. Hilldale: Laurence Erlbaum Ass.

Rosch, E. (1988). Coherences and categorization: a historical view. In F. S. Kessel (Ed.): The Development of Language and Language Researchers, Hisllsdale: Erlbaum.

Wechsler, D. (2009). Test de Inteligencia para niños preescolares-WPPSI III. Madrid: TEA Ediciones.

Weiss, Y., Cweigenberg, H. \& Booth, J. (2018). Neural specialization of phonological and semantic processing in young children. Human Brain Mapp, 39, 4334-4348. Doi: 10.1002/hbm.24274

Wittgenstein, L. (1988). Investigaciones filosóficas. Barcelona: Crítica. 
